\title{
Compliance To Hand Hygiene Standards Amongst Health Care Providers In Selected Public Hospitals In Uasin Gishu County, Kenya
}

\author{
Sharon Jerop Koech *, Dr. Jackim Nyamari ${ }^{* *}$, Dr. Eunice Njogu **** \\ ${ }^{*}$ Research scholar \\ ** Lecturer, Department of Environmental and Occupational Health, Kenyatta University \\ ${ }^{* * * *}$ Lecturer, Department of Food Nutrition and Dietetics, Kenyatta University \\ DOI: 10.29322/IJSRP.11.10.2021.p11823 \\ http://dx.doi.org/10.29322/IJSRP.11.10.2021.p11823
}

\begin{abstract}
Hand hygiene is a simple act of hand cleansing and the most effective measure of decreasing healthcare-associated infections among the health care workers. The infections not only lengthen the hospitalization period but also increase financial burden to individual, family and a country at large for example in Europe approximately $€ 13-24$ billion is spent annually. Hand hygiene compliance has remained unacceptably as low as $40 \%$ worldwide with the developing countries reporting a lower percentage. The broad objective of this study was to determine the level of compliance with hand hygiene standards amongst the health care providers in selected public hospitals in Uasin Gishu County. The study used the cross-sectional study design. The lower level health facilities were selected randomly while higher level health facilities were selected purposively. Sample size determination was done using Fisher's (1999) formula and Cochran's correction formula was used due to the population of health workers being below 10,000. A total of 301 sample size was arrived at and additional ten percent of the 301 sample size was included to accommodate for attrition hence having a total sample size of 331 respondents. The Simple random sampling technique was used to identify the 331 health care providers taking into consideration the use of probability proportionate to sample size technique in obtaining the number of health care providers from each health facility. The Data collection instruments included a self-administered questionnaire and observational checklist. Quantitative Data analysis was carried out by utilizing the Statistical Package for Social Sciences (SPSS) software version 20. The findings revealed a compliance rate of $49.8 \%$. Pearson's test of correlation revealed that the main determinants of compliance with hand hygiene standards were professional cadre ( $\mathrm{r}=014 ; \mathrm{P}=0.015)$, training $(\mathrm{r}=0.371 ; \mathrm{P}=<0.01)$ level of education $(\mathrm{r}=0.168 ; \mathrm{P}=0.004)$, availability of clean running water $(\mathrm{r}=0.271$; $\mathrm{P}=<0.01)$ and hand washing soap $(\mathrm{r}=0.168 ; \mathrm{P}=0.003)$. The study recommends that the policy makers and health stakeholders need to come up with a policy that ensures that the health care workers adhere to hand hygiene standards and ensure adequate provision of hand hygiene facilities so as to enhance compliance with hand hygiene standards.
\end{abstract}

Index Terms- Hand Hygiene, Compliance, Health care providers, Standards

This publication is licensed under Creative Commons Attribution CC BY.

http://dx.doi.org/10.29322/IJSRP.11.10.2021.p11823

\section{INTRODUCTION}

$\mathrm{H}$ 1.1 Background Information

and hygiene in health care refers to any type of hand cleansing performed in order to render the hands free from any form of visible dirt, pathogens or microorganisms (WHO, 2012). The act of hand hygiene is a fundamental measure of reducing any infections that can be transmitted via contact. Despite it being uncomplicated action, inadequate act of hand hygiene in hospitals is a public health concern worldwide (WHO, 2010). Hand hygiene in health is measured through Health care provider self-reporting, directly observing the health workers and patient assessment patient while the indirect method involves measuring the usage of hand hygiene facilities like the automated sinks and soap dispenser (pittet et al., 2009). Direct observation is currently recommended method of measuring compliance since it is able to timely identify hand hygiene opportunities and actions taken (WHO, 2012).

In most developed countries the compliance rate for hand hygiene practice rarely goes beyond fifty percent (Mani et al., 2010; Maxfield \& Dull, 2011). Like in the case of United Kingdom compliance rate is $32 \%$, in the USA the $50 \%$, and in Switzerland $42 \%$ (Takahashi \& Tulare, 2010).Effective compliance to hand hygiene standards in hospitals is essential in inhibiting the spread of Hospital infections, multi-drug resistant pathogens and to generally promote patient safety (Rocha, 2012). The possibility of acquiring HCAI is global and colonizes every health care facility worldwide and the exact burden estimates is unknown, this is based on the difficulty in data collection, variability in health systems throughout the world and on the argument that the diagnostic procedures of HCAI differ worldwide and most of the countries lack surveillance system (De Wandel, Maes, Labeau, Vereecken \& Blot, 2010). Approximately, two hundred thousand Healthcare Associated Infections (HIAs) in healthcare setting is reported annually in Australia (Jain et al., 2015). In European Union 4 million Healthcare Associated Infections (HIAs) occurs annually with 37000 death and 16 million lengthened hospital days due to the infections (Takahashi $\&$ Tulare, 2010). Despite the inadequate data on HCAI prevalence in Africa, the studies that were conducted in Algeria, Ethiopia, South Sudan, and Burkina Faso indicated the prevalence rates to be ranging from $2.5 \%$ to $48 \%$ (Dia et al., 2008) with a higher 
incidence in surgical wards. Hand hygiene is known to be costeffective, simple and the most feasible measure of minimizing infections yet compliance rate is low worldwide (Maingi, 2015)

Health Care-Associated Infections (HCAI) are common in that about $5 \%$ to $10 \%$ of hospitalized patients are at threat of getting the infection and it causes death worldwide (Grayson, 2009). The incidence of these infections is documented to be averagely 12.7 per hundred patients universally (Sinsam, 2016). Health Care-Associated Infections (HCAI) lengthens the hospitalization period of the patients, causes preventable deaths and incurs huge financial burden to not only an individual but their families and the nation at large. Moreover, in the USA about 80,000 deaths due to HCAI occurs yearly, and the health care cost in 2007 ranged from 28.4 - 33.8 billion US dollars (Aziz, 2014). The prevalence of HCAI in USA hospitals is about 722,000 cases plus seventy five thousand deaths as a result of the infections with intensive care unit reporting a higher number of cases than any other work unit. (Hebden et al., 2016).

In developing countries, the burden is much higher than those of Europe and USA, the prevalence rate is estimated to be 15.5 per 100 patients (Allegranzi, 2011). An estimated 1.5 million cases of HCAI is reported in which $25 \%$ of all infections acquired occurs in developing the world (Baqi et al.,2009) and on average 5\% of patients hospitalized are at risk of getting HCAI worldwide (Muhumuza et al., 2015). In emerging world, the weight of HCAI is high, therefore, there is need to re-examine the infection control strategies and improve on the surveillance system of HCAI (Allegranzi et al., 2010)

\subsection{Problem Statement}

The hands of health care providers are documented to be highly colonized by pathogens, therefore, serving as a media in cross- contamination. This is due to health care providers touching surfaces, substances, body fluids and patient skin during their routine practices (Ndegwa, 2014). Though it has been shown that the practice of hand cleansing is a key measure verified to be operative in averting HCAI and the transmission of antimicrobial resistance, literature report that health care providers come across challenges in observing hand hygiene standards. Inappropriate hand hygiene practices act as a media of infection spread in hospital wards ( De almeida, 2012) and accurately following hand hygiene procedures helps in curbing the spread of infections (Grayson, 2009) but compliance among health care providers remains a big challenge ( Joshi et al., 2013). Unsatisfactory or minute hand hygiene compliance rates in developing has been documented, Kenya being one of the countries where compliance to WHO standards is only at $38.7 \%$ (Ndegwa, 2014).

Despite the existence of such condition, and the possible impact of HCAI on the patients, inadequate studies have been done to accurately determine the level of compliance to WHO hand hygiene guidelines by health care workers in the Rural Counties (Mortell, 2012). According to Ndegwa (2014), eighty percent of Health Care-Associated Infections has been reduced due to compliance with hand hygiene recommendations in some of the hospital's settings whereas non-compliance has been witnessed in epidemiological studies, to be the main risk aspect for poor hand hygiene amongst other factors or reasons were given by the health care providers.
Uasin Gishu County has several public hospitals and cases of Health Care-Associated Infections (HCAI) have been reported with most studies citing cross-contamination has the main cause. For that reason, the current study sought to define the baseline level of hand hygiene compliance which has been acknowledged to be highly effective method of averting HCAI in health care. The study also sought to determine the factors that enhance or hinder hand hygiene practice amongst the health care providers.

\subsection{Justification of the Study}

There are numerous numbers of public hospitals including a national referral hospital in Uasin Gishu County and there has been limited study done on compliance with hand hygiene standards yet interventional studies have proven that hand cleansing lessens cases of Health Care-Associated Infections (HCAI) drastically. This study was, therefore, justified on the basis that it would generate information about hand hygiene amongst healthcare providers in the selected public hospitals in Uasin Gishu County, factors that promote or hinders compliance. The development of appropriate recommendations to stakeholders on best actions to undertake towards improving hand hygiene practice in health facilities.

\subsection{Research Questions}

1. What is the level of compliance to hand hygiene standards amongst the healthcare providers in selected public hospitals in Uasin Gishu County?

2. What influence do socio-demographic factors have on compliance with hand hygiene standards by healthcare providers in selected public hospitals in Uasin Gishu County?

3. What influence does hand hygiene knowledge have on compliance with hand hygiene standards by healthcare providers in selected public hospitals in Uasin Gishu County?

4. What influence do hand hygiene facilities have on compliance with hand hygiene standards by healthcare providers in selected public hospitals in Uasin Gishu County?

\subsection{Objectives of the Study}

\subsubsection{Broad objective}

To assess compliance to hand hygiene standards amongst the health care providers in selected public hospitals in Uasin Gishu County.

\subsubsection{Specific objective}

1. To determine the level of compliance to hand hygiene standards amongst the healthcare providers in selected public hospitals in Uasin Gishu County

2. To find out the influence of socio-demographic factors on compliance with hand hygiene standards by healthcare providers in selected public hospitals in Uasin Gishu County

3. To establish the influence of hand hygiene knowledge on compliance with hand hygiene standards amongst healthcare providers in selected public hospitals in Uasin Gishu County

4. To examine the influence of hand hygiene facilities on compliance with hand hygiene standards amongst 
healthcare providers in selected public hospitals in Uasin Gishu County

\subsection{Significance of the Study}

The results of the study are beneficial to the policy makers majorly the Ministry of Health and county government of Uasin Gishu County in that they are able to rethink their available strategies in order to curb Health Care-Associated Infections (HCAI) which are a burden to the health care system. The study also provides a foundation for future researchers and improves on the present literature for reviews.

\subsection{Conceptual Framework}

The study conceptual framework was grounded on the association between both the independent and dependent variables. The independent variables included; socio-demographic factors, hand hygiene facilities, hand hygiene knowledge. The dependent variable was compliance to hand hygiene standards. In this study, the behavior of the independent variables influences the outcome. Figure 1.1 further illustrates the relationship between the variables (independent and dependent).

\section{INDEPENDENT VARIABLES}

\section{DEMOGRAPHIC FACTORS \\ * Age \\ * Sex \\ * Occupation \\ * Level of education \\ * Job cadre}

\section{HAND HYGIENE} KNOWLEDGE

* Heard of hand hygiene WHO standards

* Trainino an hand hvoriene

\section{HAND HYGIENE}

\section{FACILITIES}

* Sinks with running water

* Hand rub dispensers and portable

* Towel or Tissue

Figure 1.1: Conceptual framework

Source: Author

\section{LITERATURE REVIEW}

\subsection{Introduction}

This chapter focuses on the reviewed literature under the following subheadings; Hand Hygiene in Healthcare among Health Care Workers, hand hygiene compliance, factors associated with hand hygiene compliance (socio-demographic factors, hand hygiene knowledge, availability of hand hygiene facilities) and summary of literature review.

\subsection{Hand Hygiene in Healthcare among Health Care Workers}

Hand cleansing with the use of soap with water has remained a practice of personal hygiene for eras and has been entrenched in cultural and religious practices (Anarghet et al., 2013). Health care-associated infections and hand washing linkage was established in mid-1800 by Ignaz Semmelweis who is considered the father of hand hygiene. Semmelweis noticed that post-partum mortality rates ascribed to puerperal fever differed among clinics in that there was alarmingly high maternal mortality in one clinic due to puerperal fever as compared to the other.

He further noted that most health care providers went straight to the maternity room after performing autopsies, and their hands had erratic smell even after hand washing with soap (Mathur, 2011) which led to his recommendations on the utilization of the chlorine-lime mixture to wash hands. Regardless of most hospitals adopting CDC, and HICPAC provisions on hand washing, the compliance of health care providers to these standards has remained low (Jang et al., 2010).

World Health Organization (WHO) in 2005 launched worldwide hand hygiene campaign based on the slogan "clean care is safe care" which is geared towards patient safety (Magiorakos et al., 2009). The following year they published draft recommendations on hand cleansing which they later made public in May 2009 after implementation and testing of hand hygiene 
procedures based on the global patient safety program "SAVE LIVES: clean your hand" (WHO, 2010). In 2008 World Health Organization declared $15^{\text {th }}$ October to be global hand washing day which has been practiced annually. Despite the efforts such as the introduction of guidelines guiding hand hygiene, hand hygiene practice amongst the health care providers remains a challenge and previous studies show a significant linkage between HCAI and low compliance to the standards.

The most known method microorganisms are conveyed from an individual to another person or object is through hands (WHO, 2009). People contaminate their hands through coughing or sneezing in which they touch surfaces or touch each other without cleansing hands thus transmit pathogens. This practice becomes a concern, when a health provider does undertake hand hygiene precautions then attend to vulnerable individuals whose immunity is weakened (Srigley, Furness, \& Gardam 2016). According to Tajeddin et al, (2016), 34.5\% of the frontline Health professionals' hands were contaminated with microbes and the patient's files were contaminated thirty two percent of the time.

Zimlichman et al, (2013), indicated that Healthcare Associated Infections (HIAs) are costly to the health system in that they lengthen patient hospitalization, increase treatment cost, promote antibiotic resistance, and increase patient mortality. Azim, Juergens, \& McLaws (2016), documented that the most efficient and cheapest way to thwart HIAs is via the process of practicing the recommended procedures of hand cleansing. Disturbingly, the current hand hygiene compliance rate is low worldwide ranging from 40-60\% with Sub-Saharan Africa reporting even lower compliance rates (Srigley, Furness, \& Gardam, 2016). There are various microbes that colonize the hand skin. These include the Resident flora which cannot be merely eliminated through simple hand washing and the Transient microbes which are highly associated with most hospital infections and can be eliminated via hand washing (Kingston, O'Connell, \& Dunne, 2016)

Poor hand washing amongst health workers in the developing nations are due to inadequate access to and poor use of WASH services or facilities in the health facility (UNICEF \& UNICEF, 2016).During hospitalization, patients are exposed to microbes which are responsible for HCAI causation depending on the agent's virulence, environment and host factors (WHO, 2012).In the year 2009 the World Health Organization launched recommendations on hand hygiene in health care and the First Global Patient Safety Challenge, "Clean Care is Safer Care," program has dedicated its attention promoting uptake of hand hygiene practice in the health system through implementation of viable interventions (Abdella, 2014).

A study in UK cited $38 \%$ of hospital re-admissions are as a result of Healthcare Associated Infections (HIAs) (Diller et al., 2014). In developing countries, Healthcare Associated Infections (HIAs) has been taken seriously and several multimodal interventions has been introduces with key focus on hand hygiene. The interventions have proven to decrease Healthcare Associated Infections (HIAs) significantly thus reduce deaths, cost of medication and reduce days of hospitalization. (Jemal, 2018).

A wide array of promotional approaches for hand hygiene enhancement have been brain-stormed and hand hygiene is singled out to be highly effective in tackling HCAI and improving patient well-being in health care (Maingi, 2015). The World Health
Organization identifies the hand hygiene opportunities which incorporate; before touching aseptic procedures or a patient and after coming into contact with a patient, patient environment or body fluid exposure.

\subsubsection{Hand Hygiene Compliance in Healthcare among Health Care Workers}

The compliance rate of hand hygiene in healthcare is measured as per the WHO guidelines which use five core indicators popularly identified as "My Five Moments for Hand Hygiene" approach which incorporates the following five events; before touching a patient, before aseptic procedures, after body fluid exposure, after touching a patient and after touching patient surroundings (WHO, 2009).

Whitby et al. (2006) argue that the low compliance rates are as a result of health workers practicing hand hygiene only when they perceive that their hands are dirty. Studies in developed countries such as the one done in two rural hospitals in Indonesia found out that hand hygiene compliance was 20\% (Marjadi \& Mclaws, 2010). Moreover, Ayse et al. (2014), in a research done at Istanbul university hospital facility established that the overall compliance rate was $37 \%$. In Ethiopia, hand hygiene overall compliance rate is at $38.9 \%$ averagely (WHO, 2009) while that of Kenya according to Ndegwa (2014) does not differ much with that of Ethiopia. In Embu hospital, 53.4\% of the health workers had low levels of compliance (Maingi, 2015). There is limited information on the hand hygiene practice in the hospitals specifically in developing countries.

In Saudi Arabia hospitals, Mahfouz, El Gamal, \& Al-Azraqi, (2013) reported Hand hygiene compliance rate of $41 \%$ while Alsubaie et al. (2013), reported 58\% of compliance rate among the health care workers in ICU. They cited risk factor for noncompliance has failure to correctly recognize a hand hygiene opportunity and carry out an appropriate hand hygiene action. In Malawi, Hand hygiene was reported to be $23 \%$ among the clinicians in Central Hospital, unavailability of hand sanitizers, negligence and increased work load were mentioned to be the key reasons for low compliance rate (Kalata, Kamange, \& Muula, 2013). Multimodal interventions conducted in eight hospitals across USA improved adherence to hand hygiene standards from $47.5 \%$ to $81 \%$ (Sickbert-Bennett et al., 2016). Several research studies identified factors such as professional category, gender, availability of hand hygiene facilities, failure to identify hand hygiene opportunities as factors contributing to low compliance rates.

\subsection{Factors Associated with Hand Hygiene Compliance among Health Care Workers}

Several factors such as socio-demographic characteristics and knowledge have been seen to influence compliance to hand hygiene standards among the health care providers. These factors as follows:

\subsubsection{Socio-Demographic Factors}

Several studies have noted that compliance among nurses is better than doctors (WHO, 2012). Compliance differed by profession amongst the health care providers at a tertiary university hospital in Istanbul whereby nurses recorded $41.4 \%$ 
compliance rate whereas the doctors reported $31.9 \%$ (Ayse et al., 2014).

Sakihama et al. (2016) noted that compliance rate at a teaching hospital in Japan differed among physicians $(15 \%)$ and nurses $(31 \%)$. He also observed that the compliance rate was discouragingly lower than those from similar international studies with hospitals that had infection control unit reporting better compliance rate than those who didn't have.

According to Gilbert (2014), nurses are highly probable to comply with hand hygiene standards than the doctors. Doctors are influential people in the hospital, therefore, their attitudes and practices towards hand hygiene influence the compliance of other health workers (Jang et al., 2010). Kowit et al., (2013) observed that nurses complied more than the physicians to Hand hygiene guidelines and in three Kenyan hospitals. Taneja \& Mishra (2015), found that age and years' experience to have significant positive association with hand washing.

Ndegwa (2014) reported similar observation whereby the compliance rate of the doctors and clinicians was at $22 \%$, and those of nurses was higher at $31 \%$. Gilbert (2014), cited that nurses were likely to practice hand hygiene standards as opposed to doctors who often failed to identify hand hygiene opportunities citing commitments.

Kowitt et al. (2013), further noted significant differences in hand hygiene compliance between the doctors (78\%) and nurses $(84 \%)$. Joshi et al. (2013), found that cleansing of hands was better among the nurses as compared to other health professionals. He observed that the frequency of hand washing was almost 100 percent after contact to body fluids or blood with over $90 \%$ of the health workers agreeing that hand hygiene practice prevents the acquisition of health care associated infections and shortens patient hospitalization period.

Langoya and Fuller (2015) established that the age of the health care providers was associated with training on hand hygiene practice as those who were not trained were older than those trained. Diller et al., (2014) establish the age of health care workers to be an important influencer of hand hygiene. Sethi et al. (2012) reported an improved knowledge amongst the physicians as compared to nurses, therefore, concluding that the level of knowledge and profession may be associated. In contrast, Langoya and Fuller (2015) found out that there was no connection between hand hygiene knowledge and educational level. Yawson and Hesse (2013) cited that both physicians and nurses had low compliance with practicing hand hygiene. There is inadequate information on the link between socio-demographic factors and compliance with hand hygiene standards, therefore, this study will complement studies done in the past both in developed and developing countries.

\subsubsection{Hand Hygiene Knowledge and Compliance}

In Cambodia, the incidence of surgical site infections ranged from $32 \%$ to $1 \%$ in 2014 after hand hygiene education (Sansam, 2016). In a 456-bed hospital in Bamako, an education promotion strategy increased the compliance to hand hygiene standards from $8 \%$ at the start of the intervention to $21.8 \%$ at the end of the intervention (WHO, 2009). Tada et al. (2014) mentioned that having knowledge on infection prevention was an important predictor of hand hygiene compliance.
According to Jemal (2018), $66 \%$ of the health professionals were knowledgeable about hand washing while $34 \%$ were not knowledgeable at Dubti Referral hospital, Ethiopia. Results from research carried out at Gibe Hospital Ethiopia reported $82.9 \%$ of the health care workers had good knowledge while only $17 \%$ reported to have poor knowledge (Alemu et al., 2015).

The outcomes of a research carried out in a hospital West Africa, Nigeria indicated that $82.4 \%$ of the study participants had satisfactory level of knowledge while $17.6 \%$ had unsatisfactory level of knowledge on hand hygiene standards. Also, the observation from the study shown that $42.2 \%$ of the health workers washed their hands with soap always while $34.3 \%$ and $23.5 \%$ practiced hand washing with soap intermittently and never respectively (Ojong et al., 2014).

In Nigeria, $93.2 \%$ of the health providers were conscious of the presence of the hand hygiene standards and $50.3 \%$ of the demonstrated good knowledge in hand hygiene (Tobin et al., 2013). Abdella (2014) reported that having prior training and knowledge about hand hygiene guidelines influence compliance in Ethiopia. Contrarily, Perez-Perez et al. (2015) argued that having undergone training does not necessarily guarantee good knowledge of hand hygiene standards. In Kenyatta National Hospital (KNH) the clinicians who had received basic and professional training demonstrated excellent knowledge on hand cleansing in health care (Ngugi, 2012). Mweu (2012) found out a significant association between hand cleansing and the levels of knowledge health care providers at Garissa Hospital. Similarly, Maingi (2015) reported a substantial association between knowledge and compliance with hand hygiene standards. Conversely, lack of awareness on HCAI, having insufficient information on the Hand cleansing practice, inadequate WASH facilities and inability to spot the hand cleansing occasions during patient care are barriers to proper hand hygiene practice (WHO, 2012).

\subsubsection{Availability of Hand Hygiene Facilities and Compliance with Hand Hygiene Standards}

Maxfield \& Dull (2011) suggest that by putting posters in places where there are hand washing facilities promotes hand washing since it will serve as visual reminders as one performs hand washing. Inadequate liquid soap dispensers and hand rub dispensers in the health amenities are responsible for poor compliance in Ghana (Yawson \& Hesse, 2013).

Amoran and onwube (2013) highlighted the lack of infection prevention equipment as the main reason for small uptake of hand hygiene practice in Nigeria. In Ghana, Yawson \& Hesse (2013) showed that insufficient facilities for hand hygiene specifically clean running water and soap was the main contributor to low compliance rates amongst health care providers. Abdella et al. (2014) mentioned the lack of disposable towels and other health facilities like soap as the strong predictors of practicing hand hygiene.

Ngugi (2012), also identified unavailability of disposal towels, soap dispensers and clean running water in Kenyattta National Hospital. An interventional study done in England in which hand hygiene facilities were made available and easily accessible, the compliance improved from eighty percent at the start of the intervention to $95 \%$ at the finale of the intervention (Azim, Juergens, \& McLaws, 2016). Watson (2016) also 
demonstrated the positive impact of availability of hand hygiene facilities on compliance rates. Abdella et al. (2014), pointed out water scarcity in hospital setting as one of the common hindrances to proper hand cleansing practice in Ethiopian hospital.

Most studies done in developing countries have shown that limited resources contribute to low compliance with hand hygiene standards, for example, absence or insufficient basic commodities such as running water in the healthcare setting (UNICEF \& UNICEF, 2016). This study seeks to identify the immediate challenges and to provide cost-effective recommendations on hand hygiene facilities.

\subsection{Summary of Literature Review}

The concept of Hand Hygiene in Healthcare has been in place for decades and inadequate hand washing is associated to causing hospital infections in which $25 \%$ of 1.5 million cases worldwide occur in developing the world (Baqi et al., 2009). According to WHO (2012), compliance with hand hygiene standards is below $50 \%$ worldwide and this percentage in developing world is discouragingly low. The low compliance rate in developing world has been associated with poverty, lack of hand hygiene facilities and increased workload (UNICEF \& UNICEF, 2016).

According to (Allegranzi et al., 2010), multimodal interventions have been proved to be operational in sustaining compliance to hand hygiene standards although the level of compliance is still scantly known due to limited research on the same. WHO (2012) document that insufficient or inconveniently allocated cleansing materials are a hindrance to optimal compliance hand hygiene practices? Proper hand hygiene practices have demonstrated success in reduction of Healthcare Associated Infections (HIAs) such as skin infections, and respiratory tract infections. Although, interventions have shown that if hand hygiene standards are followed adequately by the health care workers, the Healthcare Associated Infections (HIAs) will reduce significantly by $15-30 \%$ but the observational studies still record low compliance of less than $40 \%$ worldwide (Maingi, 2015)

The disparity in the compliance level of hand hygiene practice amongst various professional cadres among the health care workers is alarming yet they are all exposed to various training. Despite the existence of the hand hygiene standards worldwide, the compliance with hand hygiene standards is still a major problem but the burden lies majorly in the developing countries due to poverty, mismanagement of funds, lack of awareness and insufficient knowledge on hand hygiene practices. This study will look into investigating factors mentioned in previous studies to influence compliance of health workers with hand hygiene standards. These factors include; availability of hand hygiene facilities, knowledge and socio-demographic characteristics.

\section{MATERIALS AND METHODS}

This chapter describes the materials and methods that were used in the research study. The following are discussed in the chapter; study design, location of the study, study variables, study population, research criteria, sampling techniques, sample size determination, and the research instruments. The chapter also discusses how pretesting of research instruments were carried out, reliability, validity and the data collection techniques. The chapter concludes by discussing the ethical considerations and the data analysis.

\subsection{Study Design}

A cross-sectional study design was used to obtain the research data. The study design was most appropriate in the study since it enables the researcher to collect data of a huge population within a short period of time. This research study involved a sample of health care workers being selected in public hospitals in Uasin Gishu County. The selected sample voluntarily helped to answer research questions.

\subsection{Location of the Study}

The study was done in Uasin Gishu County which is situated in mid-west of Rift Valley, 330km northwest of Nairobi, Kenya. The county has six sub-counties with approximately 894,179 people (KNBS, 2009). The study location was purposively selected. According to Uasin Gishu county health strategic and investment plan 2013-2018, the county has approximately 1901 health care providers and 90 public health facilities that are 68 dispensaries, 18 health centers, 2 sub-county hospitals, one county hospital, and one National referral hospital.

\subsection{Study Variables}

In this study, the dependent variables were compliance to hand hygiene standards by health care providers in the hospital while the independent variables were; factors that influence compliance to hand hygiene standards such as socio-demographic factors, availability of hand hygiene facilities and hand hygiene awareness.

\subsection{Study Population}

The study focused on all the health care providers in selected Public hospitals in Uasin Gishu County.

\subsection{Inclusion Criteria}

Health care providers aged above 21 years and have agreed to take part in the study. Also, the Health care providers must have worked for at least a year in the facility.

\subsection{Exclusion Criteria}

Health care providers aged below 21 years. Those health care providers aged above 21 years and have not agreed to take part in the study will be excluded from research. Also, heath care providers who have worked less than one year in the facility will be excluded.

\subsection{Sampling Techniques}

Simple random sampling was used to select level III \& II (lower level) 1 health facilities that is 12 out of 18 health centers (level III) and 45 out of 68 dispensaries (level II) while purposive sampling was used to select higher-level facilities that are two subcounty hospitals (Ziwa Sirikwa and Huruma sub-county hospital), county hospital that is Uasin Gishu District hospital and the national referral hospital (Moi Teaching and Referral Hospital) to avoid omitting them from the study since they execute key operations. Probability proportionate-to-size sample was used to obtain the number of health care providers from each health facility level as shown in table 3.7. The list of health care providers obtained served as the sampling frame such that simple random sampling was carried out ensuring that sample was drawn from all the cadres of health workers. 
Table 3.1. Calculated probability proportionate to size sample

\begin{tabular}{lll}
\hline Health facility level & $\begin{array}{l}\text { Population of health } \\
\text { care workers }\end{array}$ & Sample size \\
National hospital & 1360 & 215 \\
County hospital & 105 & 17 \\
Sub-county hospitals & 134 & 21 \\
Health centers (level & 108 & 17 \\
III) & & \\
Dispensaries (Level & 194 & 31 \\
II) & & \\
Total & $\mathbf{1 9 0 1}$ & $\mathbf{3 0 1}$ \\
\hline
\end{tabular}

Source: Health facility human resource data

\subsection{Sample Size Determination}

This was determined by using the Fisher's (1999) formula:

$\mathrm{n} \quad=\quad \frac{z^{2} p q}{d^{2}}$

Where

$\mathrm{z}=$ standard normal deviate corresponding to $95 \%$ confidence level (=1.96)

$\mathrm{n}=$ the required minimum sample size (if the population is more than 10,000)

$\mathrm{p}=$ Estimated proportion of health care workers who comply to hand hygiene standards by the WHO (Taken as $37 \%$ from previous studies).

$\mathrm{d}=$ degree of accuracy; set as 0.05

$\mathrm{n}=\left(1.96^{2} \times 0.37 \times 0.63\right) / 0.05^{2}$

$=358$

Cochran's correction formulae will be used to calculate the sample size since the population is less than 10,000 .

$$
n=\frac{n_{0}}{(n-1)}
$$

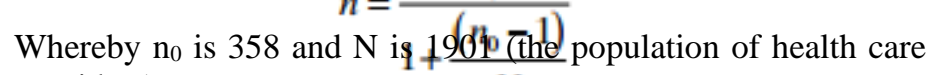
providers)

$=358 / 1+\left(\left(\mathrm{n}_{0}-1\right) / 1901\right)$ $N$

$=301$

$10 \%$ of the calculated sample size was added to accommodate for attrition thus the sample size will be;

$=301 * 10 \%$

$=30$
$=30+301$

$=331$

\subsection{Research Instruments}

A standardized questionnaire (see Appendix 3) and World Health Organization observational checklist (see Appendix 4) was used to collect the data. A self-administered questionnaire was constructed based on demographic characteristics, knowledge of hand hygiene guidelines and the availability of hand hygiene facilities. Observations were conducted in order to observe hand washing opportunities amongst the health care providers and availability of hand washing facilities.

The WHO policy documents, the hospital documents, the published information, and reports were used in the literature review.

\subsection{Pre-Testing of Research Instruments}

Ten percent of the health care workers questionnaires (30) were pre-tested in Plateau mission hospital in Uasin Gishu County. The objective of the pre-test was to ensure consistency, precision and applicability of the research questions. The research questions, statements and ambiguity were corrected as per the outcome of the pre-test.

\subsection{Validity}

The instrument was reviewed by the experts to ensure that they are valid. Internal validity was achieved by ensuring that the instruments were structured to address the study objectives and research questions while external validity was achieved through utilization of simple random sampling during the selection process so as to ascertain that the findings obtained represented to the whole study population.

\subsection{Reliability}

The Cronbach's alpha technique in this study defined the internal consistency of the study questionnaire such that the technique determined if the questions or measurement items are related to each other. Perfect consistency (instrument is more reliable) is obtained when the coefficient is close to 1.0 . When the coefficient is greater than 0.6 , it is considered reliable while it is considered very reliable when greater than 0.8 . This study, therefore, found Cronbach's alpha coefficient of 0.673 as shown in table 3.2 thus considered reliable.

Table 3.2: Reliability

\section{Reliability Statistics}

Cronbach's Alpha
Number of Items

24
Source: Cronbach's Alpha coefficient

\subsection{Data Collection Techniques}

Considering the extensive data collection locations four research assistants with a basic training on research and a background knowledge in data collection were recruited. Training on the aim and the objective of the research study was conducted. The research assistance were also, thoroughly trained on sampling, administration of research instrument, pre-testing of the questionnaires, interviewing techniques and selection criteria. They were also trained on ethics and the overall objective of the study. The research assistants were also required to conduct observations whereby one was assigned a health facility and required to make observations and record the findings 
appropriately. They were trained on how to conduct observations, how to fill the observational checklist and ethics maintenance.

\subsection{Data Analysis}

The data was entered into SPSS (statistical package for social sciences) software version 20 then the data was summarized using descriptive statistics. The analyzed data was presented as frequencies, percentages, mean and cross tabulations. Testing of associations between independent variables (socio-demographic factors, hand hygiene facilities, hand hygiene knowledge) and the dependent variable (compliance with hand hygiene) was done using Pearson's correlation coefficient and t-test.

\subsection{Ethical Considerations}

Approval to conduct research was obtained from Kenyatta University graduate school. Ethical clearance was obtained from Kenyatta University Ethics Review Committee. Research permit was obtained from NACOSTI. Consent to undertake the study was gotten from Uasin Gishu Health Department. Informed consent from each of the respondents was sought before any interviews and the purpose of the research was clearly expounded to them. Research participants were asked to take part voluntarily whereby anonymity and confidentiality were maintained throughout the study. Study participants had the freedom to discontinue from the study anytime.

\section{RESULTS}

\subsection{Introduction}

This section concentrates on the results of the study. The respondents were asked several questions as per the research questions and the study objectives. The results of the study are presented as follows; socio-demographic characteristics of the respondents, Hand hygiene knowledge, availability of hand hygiene facilities and their corresponding correlations with compliance with hand hygiene standards. The ultimate aim of the study was to determine the level of compliance to hand hygiene standards among the health care providers in selected public hospitals in Uasin Gishu County.

\subsection{Response Rate}

4.2.1 Response Rate of Questionnaires

The study administered 331 questionnaires in which 9 questionnaires were not returned thus 322 questionnaires were returned from the field. The 322 returned questionnaires were subjected to data cleaning and 21 questionnaires were deemed invalid due to incomplete data. A total of 301 questionnaires were considered valid for data analysis. Table 4.1 presents the questionnaires response rates.

Table 4.1: Questionnaires response rate

\begin{tabular}{llll}
\hline $\begin{array}{l}\text { Questionnaires } \\
\text { administered }\end{array}$ & $\begin{array}{l}\text { Questionnaires } \\
\text { administered and } \\
\text { returned }\end{array}$ & $\begin{array}{l}\text { Questionnaires retuned and } \\
\text { valid for analysis }\end{array}$ & $\begin{array}{l}\text { Percentage } \\
\text { Response Rate }(\%)\end{array}$ \\
331 & 322 & 301 & 90.9 \\
\hline
\end{tabular}

Table 4.1 present the overall questionnaires response rate of $90.9 \%$ for the respondents sampled from selected public hospitals in Uasin Gishu County. Mugenda and Mugenda (2003) coined that any response rate that is over $70 \%$ is considered very good for a research study analysis, grounded on this theory this study response rate was $90 \%$ thus deemed usable for data scrutiny. The excellent response rate was credited to prior pre-testing of the questionnaires and adequate training of research assistants.

\subsection{Socio-demographic characteristics of the respondents}

Table 4.2 present data on socio-demographic characteristics of the study respondents. Findings shows that the female $(56.1 \%)$ respondents were more than the male $(43.9 \%)$ participants. The average age of the study participants was 34.8 years with a median of $36-40$. The nurses $(65.8 \%)$ recorded the highest number of respondents as compared to laboratory technicians (12.3\%), clinical officers $(12.0 \%)$, doctors $(5.3 \%)$, and the physiotherapists $(4.7 \%)$. Most of the respondents had diploma (66.4\%) followed by those with certificate $(11.6 \%)$, bachelors $(10 \%)$, and those with masters were the least $(3 \%)$. 
Table 4.2: Socio-demographic characteristics of the respondents $(n=301)$

\begin{tabular}{|c|c|c|}
\hline Variable & Frequency & Percentage $(\%)$ \\
\hline Gender Male & 132 & 43.9 \\
\hline Female & 169 & 56.1 \\
\hline \multicolumn{3}{|l|}{ Age } \\
\hline $21-25$ & 23 & 7.6 \\
\hline $26-30$ & 73 & 24.3 \\
\hline $31-35$ & 65 & 21.6 \\
\hline $36-40$ & 86 & 28.6 \\
\hline $41-45$ & 28 & 9.3 \\
\hline $46-50$ & 16 & 5.3 \\
\hline $51-55$ & 10 & 3.3 \\
\hline \multicolumn{3}{|l|}{ Professional Cadre } \\
\hline \multicolumn{3}{|l|}{ Doctor } \\
\hline Nurse & 16 & 5.3 \\
\hline Clinical officer & 198 & 65.8 \\
\hline Laboratory technician & 36 & 12.0 \\
\hline Physiotherapist & 37 & 12.3 \\
\hline Level of education & 14 & 4.7 \\
\hline \multicolumn{3}{|l|}{ Masters } \\
\hline Bachelors & 9 & 3 \\
\hline Higher diploma & 30 & 10 \\
\hline Diploma & 27 & 9 \\
\hline \multirow[t]{2}{*}{ Certificate } & 200 & 66.4 \\
\hline & 35 & 11.6 \\
\hline
\end{tabular}

\subsection{Compliance with hand hygiene standards}

The results of the study in table 4.3 indicate that all (100\%) of the study participants wash hands after fluid exposure, $94.4 \%$ before a clean procedure, $93.7 \%$ after touching a patient, $86.4 \%$ after touching patient surrounding and $21.3 \%$ before touching a patient. Moderate $(69.1 \%)$ number of study participants indicated usage of hand rubs while $30.9 \%$ reported not to use any hand rub. The general compliance rate was $49.8 \%$.

Table 4.3: Compliance with hand hygiene $(n=301)$

\begin{tabular}{lll}
\hline Variable & Frequency & $\begin{array}{l}\text { Percentage } \\
(\boldsymbol{\%})\end{array}$ \\
\hline In which situations do you wash your hands & 64 & 21.3 \\
Before touching a patient & 237 & 78.7 \\
Yes & & \\
No & 284 & 94.4 \\
Before a clean procedure & 17 & 5.6 \\
Yes & & \\
No & 301 & 100 \\
After body fluid exposure & 0 & 0 \\
Yes & & \\
No & 282 & 93.7 \\
After touching a patient & 19 & 6.3 \\
Yes & & \\
No & 260 & 86.4 \\
After touching a patient surrounding & 41 & 13.6 \\
Yes &
\end{tabular}

This publication is licensed under Creative Commons Attribution CC BY. 


\begin{tabular}{lll} 
Do you routinely use an alcohol-based hand rub & & \\
Yes & 208 & 69.1 \\
No & 93 & 30.9 \\
Overall compliance with hand hygiene standards & 150 & 49.8 \\
$\quad$ High & 151 & 50.2 \\
\hline Low
\end{tabular}

\subsection{Socio-Demographic Factors and Compliance with Hand Hygiene}

Table 4.4 indicates the link between socio-demographic characteristics and compliance with hand hygiene guidelines.

Table 4.4: Correlation between socio-demographic factors and compliance with hand hygiene

\begin{tabular}{|c|c|c|c|c|c|}
\hline & $\begin{array}{l}\text { Overall } \\
\text { compliance with } \\
\text { HH guidelines }\end{array}$ & Gender & Age & $\begin{array}{l}\text { Professional } \\
\text { cadre }\end{array}$ & $\begin{array}{l}\text { Level o } \\
\text { Education }\end{array}$ \\
\hline $\begin{array}{c}\text { Pearson } \\
\text { Overall compliance withCorrelation }\end{array}$ & 1 & -.051 & .043 & $.140^{*}$ & $.168^{* *}$ \\
\hline HH guidelines & & .381 & .458 & .015 & .004 \\
\hline $\mathrm{N}$ & 301 & 301 & 301 & 301 & 301 \\
\hline
\end{tabular}

The results show that there was no statistically significant association between gender and compliance with hand hygiene guidelines $(\mathrm{P}=0.381 ; \mathrm{r}=-0.051)$. Also, the correlation between age and the compliance with hand hygiene guidelines show that there was no significant correlation between them in which the P-value is 0.458 and $r=0.043$. On the other hand, it is apparent that there is statistically significant association between the professional cadres of the respondents $(\mathrm{r}=140 ; \mathrm{P}=0.015)$, their level of education $(\mathrm{r}=168 ; \mathrm{P}=0.004)$ and compliance with hand hygiene guidelines.

\subsection{Distribution of Health Workers in Health Facility Level}

Table 4.5 present data on the number of health care providers who took part in the study in the hospital facilities sampled. Results indicate that $65.8 \%$ of the health care workers sampled were from National hospital, $8.3 \%, 10.6 \%, 7.3 \%$ and $8 \%$ of the health care workers were sampled from county, sub-county, health centers and dispensaries respectively.

Table 4.5: Distribution of health workers in health facility level

\begin{tabular}{|c|c|c|c|c|c|c|c|}
\hline \multirow[t]{2}{*}{ Hospital level } & \multicolumn{7}{|c|}{ Professional cadre } \\
\hline & Doctor & Nurse & $\begin{array}{l}\text { Clinical } \\
\text { officer }\end{array}$ & $\begin{array}{l}\text { Laboratory } \\
\text { Technician }\end{array}$ & Physiotherapist & Total & $\begin{array}{c}\text { Percentage } \\
(\%)\end{array}$ \\
\hline & 11 & 128 & 18 & 29 & 12 & 198 & 65.8 \\
\hline \multirow{4}{*}{$\begin{array}{l}\text { National } \\
\text { county } \\
\text { sub-county } \\
\text { Health centres } \\
\text { Dispensaries }\end{array}$} & 3 & 12 & 5 & 4 & 1 & 25 & 8.3 \\
\hline & 2 & 23 & 3 & 3 & 1 & 32 & 10.6 \\
\hline & 0 & 15 & 6 & 1 & 0 & 22 & 7.3 \\
\hline & 0 & 20 & 4 & 0 & 0 & 24 & 8.0 \\
\hline Total & 16 & 198 & 36 & 37 & 14 & 301 & 100.0 \\
\hline
\end{tabular}

Table 4.5 indicates data on the distribution of the study participants (health care workers) as per their professional cadre in the sampled health facilities. Results indicate that majority of the study participants were sampled from the national level of hospital. There were 11 doctors, 128 nurses, 18 clinical officers, 29 laboratory technicians and 12 physiotherapists. The health centres and the dispensaries reported the least number of health care workers with both having no doctor sampled. The health centres had 15 nurses, 6 clinical officers and one laboratory technician while the dispensaries had 20 nurses, and 4 clinical officers as the research respondents.

\subsection{Level of Hospitals}


Most of the health care providers (111) at the higher level hospital (national) had medium knowledge; seventy three of them had high knowledge while fourteen of them had low knowledge. The county hospital recorded zero low level of knowledge with most (17) of them having medium level of knowledge and this can be attributed to continuous training among the health care workers.
Also, seventeen health workers from the sub county hospital recorded medium level of knowledge while 15 and 10 health care providers from lower level health facilities that is health centers \&dispensaries had respectively had medium level knowledge of health centers and dispensaries as shown in the table 4.6

Table 4.6: Hospital level and level of knowledge of health care providers

\begin{tabular}{llllll}
\hline \multicolumn{5}{c}{ Hospital level * Level of knowledge Crosstabulation } & \\
\hline Count & & \multicolumn{2}{l}{} & \\
& & \multicolumn{2}{l}{ Level of knowledge } & & Total \\
& Low & Medium & High & \\
& National & 14 & 111 & 73 & 198 \\
& County & 0 & 17 & 8 & 25 \\
Hospital level & sub-county & 4 & 17 & 11 & 32 \\
& Health centres & 2 & 15 & 5 & 22 \\
& Dispensaries & 5 & 10 & 9 & 24 \\
Total & & 25 & 170 & 106 & 301 \\
\hline
\end{tabular}

4.7.1: Correlations between Level of hospital and compliance with hand hygiene guidelines

Table 4.7 present data on the correlation between the hospital level and compliance with hand hygiene standards. The correlations showed insignificant correlation between the hospital level and compliance with hand hygiene standards ( $\mathrm{r}=0.061$; $\mathrm{P}=0.293$ ).

Table 4.7: Correlations between level of hospital and compliance

\section{Correlations}

\section{How is your overall compliance with HH guidelinesHospital level}

\begin{tabular}{|c|c|c|c|}
\hline \multirow{2}{*}{\multicolumn{3}{|c|}{$\begin{array}{l}\text { How is your overallPearson Correlation1 } \\
\text { compliance with } \mathbf{H H}_{\text {Sig. (2-tailed) }}\end{array}$}} & .061 \\
\hline & & & .293 \\
\hline & $\mathrm{N}$ & 301 & 301 \\
\hline \multirow[b]{2}{*}{ Hospital level } & \multicolumn{2}{|c|}{ Pearson Correlation.061 } & 1 \\
\hline & $\begin{array}{l}\text { Sig. (2-tailed) } \\
\text { N }\end{array}$ & $\begin{array}{l}.293 \\
301\end{array}$ & 301 \\
\hline
\end{tabular}

\subsection{Hand Hygiene standards knowledge}

The study participants were asked a series of questions so as to gauge their familiarity with hand hygiene standards. Table 4.6 present data on the knowledge assessment questions, level of knowledge and the calculated knowledge score. Results indicate that $90.7 \%$ (273) of the respondents have heard about hand hygiene standards while $9.3 \%$ (28) of the respondents indicated to have not heard of any hand hygiene standards. Majority (86.7\%) of the health care workers had undergone training while 13.3\% had not undergone any formal training for the last four years. Majority $(59.5 \%, 179)$ of the respondents indicated the hands of the health care providers, $20.9 \%$ (63) indicated air within the hospital, 18.6\% (56) indicated surfaces such as beds and 1\% (3) of the respondents indicated sharing of non-invasive objects as the core cause of cross-contamination of pathogens in health care system. Most (38.2\%) of the study participants knowledge score was $70 \%-79 \%$, eighty-six scored between $80 \%-89 \%$ and only 9 study participants had knowledge score above 90\%. Those participants who had knowledge score below 49\% were only 13 . Majority (56.5\%) of the study participants had medium level of knowledge with $35.2 \%$ and $8.3 \%$ had high and low level of knowledge respectively. The improved level of knowledge is attributed to high number of health workers having attended training on hand hygiene standards for the last four years. 
Table 4.8: Hand hygiene standards knowledge

\begin{tabular}{lll}
\hline Variable & FREQUENCY & VALID PERCENTAGE (\%) \\
& & \\
Have undergone training for the & & \\
last four years & & \\
Yes & 261 & 86.7 \\
No & 40 & 13.3 \\
Have heard of hand hygiene & & \\
standards & 272 & \\
Yes & 29 & 90.4 \\
No & & 9.6 \\
knowledge score & & \\
90\% and above & 9 & 3.0 \\
$80 \%-89 \%$ & 86 & 28.6 \\
$70 \%-79 \%$ & 416 & 38.5 \\
60\%-69\% & 36 & 13.6 \\
50\%-59\% & 12.0 \\
$49 \%$ and below & & 4.3 \\
Level of knowledge & & \\
Low & 25 & 8.3 \\
Medium & & 56.5 \\
High & 170 & 35.2 \\
\hline
\end{tabular}

4.8.1 Relationship between age, professional cadre and level of knowledge

Table 4.9 present data on the age, professional cadre and level of knowledge. Results show that there was positive correlation between age and level of knowledge ( $\mathrm{r}=0.111 ; \mathrm{P}=0.054)$. There was statistically negative insignificant relationship between professional cadres and level of knowledge $(\mathrm{r}=-0.039 ; \mathrm{P}=0.502)$.

Table 4.9: Present data on the age, professional cadre and level of knowledge

\begin{tabular}{lllll}
\hline Correlations & & & & \\
\hline & & & & \\
& & & & \\
& & & & \\
Level & Pearson Correlation & 1 & .111 & -.039 \\
knowledge & Sig. (2-tailed) & & .054 & .502 \\
& $\mathrm{~N}$ & 301 & 301 & 301 \\
& & & & \\
\hline
\end{tabular}

4.8.2 Correlations between hearing of hand hygiene standards, training and compliance with hand hygiene standards

Table 4.10 present data on the correlations between hearing of hand hygiene standards, training and compliance with hand hygiene standards. Results show that there is a positive correlation $(r=0.371 ; p<0.01)$ between training on hand hygiene standards and compliance with hand hygiene guideline thus the findings were statistically significant. It is evident that there is a statistically significant and positive correlation $(\mathrm{r}=0.303$; $\mathrm{p}<0.01)$ between heard of hand hygiene standards and compliance with hand hygiene standards. 
Table 4.10: Correlations between training, hearing of hand hygiene standards and compliance 3

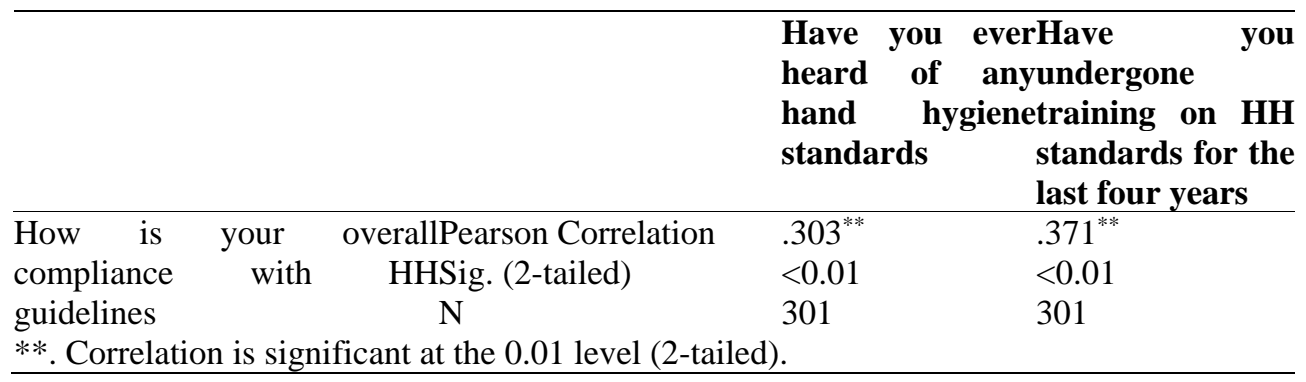

4.8.3 Correlation between level of knowledge and compliance with hand hygiene standards

Table 4.11 present data on the level of knowledge and compliance with hand hygiene standards. Results show a statistically negative insignificant relationship $(r=-0.051$; $\mathrm{P}=0.377$ ) between the level of knowledge and compliance with hand hygiene standards. This finding maybe attributed to the results of health care workers having high or medium level of knowledge plus other factors such as training on hand hygiene standards and availability of hand hygiene facilities.

Table 4.11: Correlation between level of knowledge and compliance

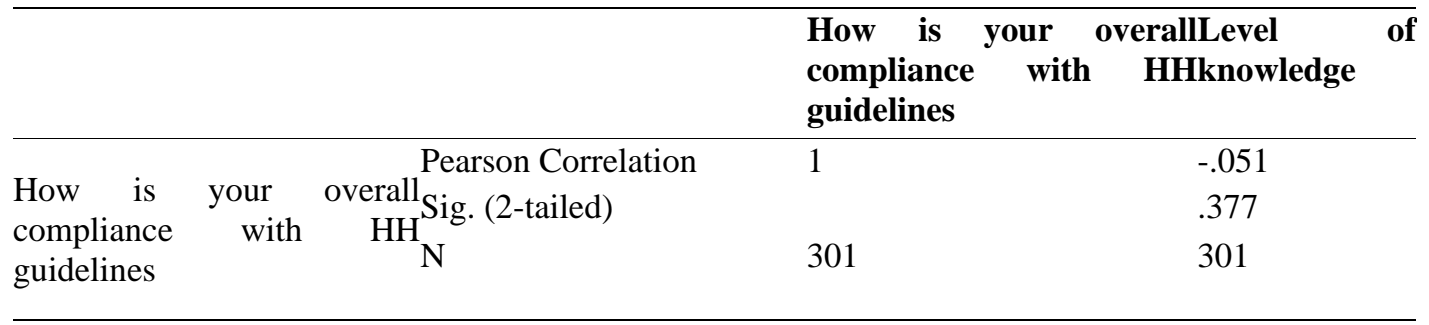

\subsubsection{Core cause of cross-contamination of pathogens between} patients.

The study participants were asked to indicate what they think is a core cause of cross-contamination of pathogens between patients. The participants were given various choices that is surfaces, health care providers' hands, sharing of non-invasive objects between patients and air within the hospital in which they were to select only one variable. Majority $(59.5 \%, 179)$ of the respondents indicated the hands of the health care providers, $20.9 \%$ (63) indicated air within the hospital, $18.6 \%$ (56) indicated surfaces such as beds and 1\% (3) of the respondents indicated sharing of non-invasive objects as shown in figure 4.1 


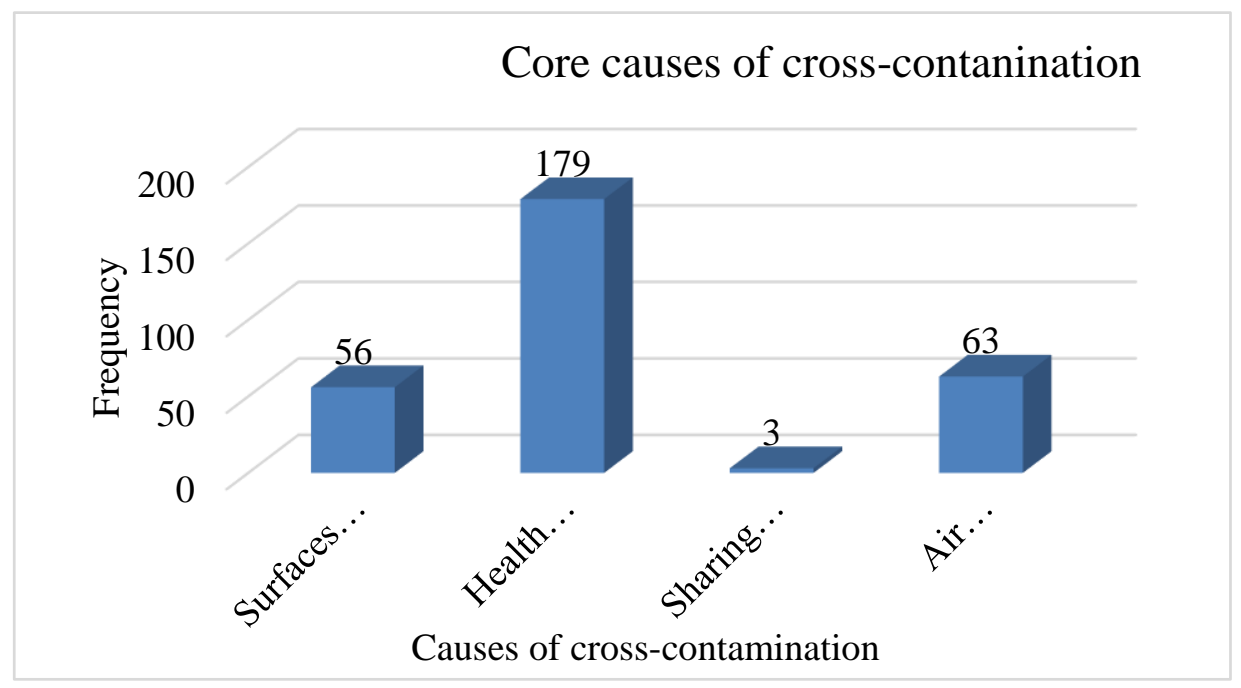

Figure 4.1. Core cause of cross-contamination between patients

\subsection{Availability of Hand Hygiene Facilities in Health Facilities}

The study participants were asked questions concerning the availability of various hand hygiene materials in the health facility. The response was as illustrated in table 4.12

Table 4. 12: Availability of hand hygiene facilities in health facilities

\begin{tabular}{llll}
\hline $\begin{array}{l}\text { Hand hygiene facilities } \\
\text { Availability of clean running } \\
\text { Water }\end{array}$ & Frequency & Valid Percent \\
\hline \multicolumn{1}{c}{ Always } & & \\
& Sometimes & 99 & 32.9 \\
& Never & 129 & 42.9 \\
& Total & 73 & 24.3 \\
Availability of alcohol-based hand rub & 301 & 100.0 \\
& Always & & \\
& Sometimes & 30 & 10.0 \\
& Never & 61 & 20.3 \\
Total & 210 & 69.8 \\
Availability of hand wipes & 301 & 100.0 \\
& Always & & \\
Sometimes & 10 & 3.3 \\
Never & 31 & 10.3 \\
Total & 260 & 86.4 \\
Availability of hand washing soap & 301 & 100.0 \\
Always & & \\
Sometimes & 99 & 32.9 \\
Never & 129 & 42.9 \\
Total & 73 & 24.3 \\
& & 301 & 100.0 \\
\hline
\end{tabular}




\subsection{1}

Availability of clean running water in health facilities

The results as shown in table 4.12 indicated that $44.8 \%$ of the respondents indicated presence of running water to be always there, $44.2 \%$ reported to be sometimes there while $11 \%$ of the respondents reported to have never been running water.

4.9.2 Availability of Alcohol-based hand rub in health facilities

Majority $(69.8 \%)$ of the respondents indicated that alcoholbased hand rub has never been within their reach, $20.2 \%$ of the respondents indicated that alcohol-based hand rub was sometimes within their reach while the minority $(10 \%)$ of the respondents reported that the alcohol based hand rub has never been within their reach as shown in table 4.12

4.6.3 Availability of hand wipes (sterile towels or disposable paper) in health facilities

Majority $(86.7 \%)$ of the respondents reported to have never been hand wipes at the hand washing water points, $10.3 \%$ reported availability to be sometimes while $3 \%$ of the respondents reported availability of the hand wipes to be always as shown in table 4.12. 4.9.4 Availability of hand washing soap in health facilities
The respondents were expected to report whether there has been availability of hand washing soap in water points. Majority $(42.9 \%)$ of the respondents reported the availability of hand washing soap to be sometimes, $32.9 \%$ reported to be available always while $24.3 \%$ of the respondents reported to have never been available as illustrated in table 4.12

4.9.5 Correlations between hand hygiene facilities and compliance with hand hygiene standards.

According to the findings as shown in table 4.13, it is evident that the availability of posters, clean running water and hand washing soap was statistically significant at $\mathrm{p}<0.01, \mathrm{p}<0.01$ and $\mathrm{p}=0.003$ respectively. In addition, the findings reported positive correlation between these variables (clean running water $r=0.271$, hand washing soap $r=0.168$ ) and compliance with hand hygiene standards. However, availability of alcohol-based hand rub ( $\mathrm{r}=$ $0.013 ; \mathrm{p}=0.822)$ and availability of hand wipes $(\mathrm{r}=-0.021$; $\mathrm{p}=0.721$ ) were statistically insignificant. There was negative correlation between availability of these two variables (alcoholbased hand rub and hand wipes) and compliance with hand hygiene standards.

Table 4.13: Correlations between hand hygiene facilities and compliance with hand hygiene standards

\begin{tabular}{|c|c|c|c|c|c|c|}
\hline & & $\begin{array}{l}\text { Compliance } \\
\text { with } \\
\text { guidelines }\end{array}$ & $\begin{array}{c}\text { Clean } \\
\text { HHrunning } \\
\text { water }\end{array}$ & $\begin{array}{l}\text { Hand } \\
\text { washing } \\
\text { soap }\end{array}$ & $\begin{array}{l}\text { Alcohol- } \\
\text { based hand } \\
\text { rub }\end{array}$ & Hand wipes \\
\hline \multirow{3}{*}{$\begin{array}{l}\text { compliance } \\
\text { with } \\
\text { guidelines }\end{array}$} & $\begin{array}{l}\text { Pearson } \\
\text { Correlation }\end{array}$ & 1 & $.271^{* *}$ & $.168^{* *}$ & -.013 & -.021 \\
\hline & HHSig. (2-tailed) & & .000 & .003 & .822 & .721 \\
\hline & $\mathrm{N}$ & 301 & 301 & 301 & 301 & 301 \\
\hline
\end{tabular}

Source: Pearson's correlations

4.10 Observational checklist results on compliance with hand hygiene standards

An aggregate of 58 health care providers were observed, in order to assess whether they could be able to identify hand hygiene opportunities and be able to carry out successful hand hygiene practice. Five hundred and fifty six hand hygiene opportunities were observed in various work units within the health facilities. Two hundred and forty-three opportunities observed were successful while the remaining three hundred and thirteen opportunities were unsuccessful. The successful opportunities were categorized as those opportunities correctly identified by the health care workers and recommended hand hygiene action taken while the unsuccessful opportunities were those opportunities either missed or unsuccessful hand hygiene action taken as shown in table 4.14. The overall observation compliance rate was $48.22 \%$.

Table 4.14: Observation results

\begin{tabular}{llll}
\hline Professional cadre & $\begin{array}{l}\text { HH Total } \\
\text { opportunities } \\
\text { observed }\end{array}$ & $\begin{array}{l}\text { HH Successful } \\
\text { opportunities }\end{array}$ & $\begin{array}{l}\text { Compliance rate }(\%) \\
\text { =HH Successful/total } \\
\text { HH opportunities } \\
\text { observed }\end{array}$ \\
\hline Doctors & 67 & 37 & 55.2 \\
Nurses & 237 & 65 & 32.3 \\
Clinical Officers & 148 & 76 & 51.4 \\
Laboratory technician & 86 & 59 & 68.6 \\
Physiotherapist & 18 & 6 & 33.3 \\
Total & 556 & 243 & - \\
Average compliance rate $(\%)$ & & 48.22 \\
\hline
\end{tabular}




\section{DISCUSSION, CONCLUSIONS AND RECOMMENDATIONS}

\subsection{Introduction}

This chapter entails discussion of study findings, comparison of the current study findings with the findings of previous studies. The chapter further provides a summary of the study, the recommendations and conclusion.

\subsection{Discussion}

5.2.1 Socio-demographic characteristics and compliance with Hand hygiene standards.

The female $(56.1 \%)$ respondents in this study were more than the male $(43.9 \%)$ respondents this is because naturally the nurses take up the largest part of human resource in hospitals and, in the past, the nursing profession was considered as a female profession. This finding is comparable to the study conducted at Mulango health facility, Uganda by Sethi et al (2012) in which the female participants were the majority.

The current study found no statistically substantial association between age $(\mathrm{p}=0.458)$, gender $(\mathrm{p}=0.381) \&$ compliance with hand hygiene whilst professional cadre $(\mathrm{p}=0.015)$ and level of education $(\mathrm{p}=0.004)$ was statistically significant. In contrast Joshi et al (2013) documented that one belonging to certain professional group does not influence one's compliance rate.

Majority (66.4\%) of the study participants had diploma level of education this is credited to the circumstance that the Kenya Medical Training College (KMTC) trains most of the health care human resource. The current study found compliance to be high among the doctors, nurses and laboratory technicians as compared to physiotherapist. This finding is coherent with Anargh et al (2013) and Sethi et al (2012) studies done in tertiary care facility in Pune, India and Mulango hospital, Uganda respectively.

\subsubsection{Compliance with hand hygiene standards}

There was a significant higher compliance rate of $(49.8 \%)$ in this study as compared to Maingi (2015) and Abdella et al (2014) who estimated the compliance rate of health care workers at Embu level four hospital, Kenya and Gondar University hospital, Ethiopia to be $46.6 \%$ and $30.8 \%$ respectively. The noticeable improvement of level of compliance with hand hygiene standards has been linked to amplified hand hygiene awareness by Ministry of Health and Infection Prevention Control Department within the country.

Ndegwa (2014) estimated a lower compliance level of $28 \%$ among the health professionals in three public hospitals in Kenya as compared to the current study (49.8\%). Contrary to current study high compliance rate, Sakihama et al (2016) found overall compliance rate between hospitals in Japan ranging from $11 \%$ to $25 \%$.

The current study indicated that $21.3 \%$ of the health workers wash their hands after touching a patient, all the health workers reported to wash hands after fluid exposure, $86.4 \%$ reported to wash hands after touching patient surrounding and $94.4 \%$ reported to during an aseptic procedure. Langoya \& Fuller (2015) found similar finding such that $75 \%$ of the health workers washed hands after touching a patient, $52.5 \%$ after fluid exposure, $43.6 \%$ after touching patient surrounding and $66 \%$ during an aseptic procedure.

This publication is licensed under Creative Commons Attribution CC BY

http://dx.doi.org/10.29322/IJSRP.11.10.2021.p11823
The utilization of alcohol-based hand rub was moderate (69.1\%) due to its unavailability in some of the health facilities and some health workers reported skin irritation due to hand rub so opted to hand washing.

\subsubsection{Hand hygiene knowledge and compliance with hand} hygiene guidelines

In this study $56.5 \%$ of the health care providers had moderate level of knowledge, $8.3 \%$ had low level of knowledge while only $35.2 \%$ has high level of knowledge. This finding was comparable to a study carried out in Embu level four hospital whereby $33.1 \%$ of the health care workers had high level of knowledge, $57.1 \%$ had medium \& 9.8\% had low level of knowledge (Maingi, 2015). This finding was lesser than that in the study done in two teaching hospitals in Mashhad, Iran revealed that $68 \%$ of the health care providers had a intermediate level of knowledge on hand hygiene, $21 \%$ and $10.6 \%$ had poor and high level of knowledge respectively (Zakeri et al.,2017). The analysis further showed that there was insignificant variance in the level of knowledge and hand hygiene training. This might be due to the status of the hospital, and nature of the study participants.

Zakeri et al. (2017) found no relationship of level of knowledge with professional cadre age, and gender. Langoya \& Fuller (2015) identified a statistically negative association between age of the study participants and their knowledge score portraying that younger health care providers had better knowledge than the old.

Majority $(86.7 \%)$ of the study participants had undergone a recommended training on hand cleansing practice for the past four years. This finding explains why three-quarter of the respondents in this study knew of the existing hand hygiene standards. In contrast, Langoya \& Fuller (2015) established that most (62.7\%) of the health care providers did not receive any formal training for the last three years.

Almost two-third of the study participants in the present study positively identified correctly the hands of the health care providers as the core cause of cross-contamination in the health facilities.

The current study participants had knowledge on WHO "Five moments "of hand hygiene in which $91.7 \%$ of the participants agreed that one should perform hand hygiene in all the "five moments". This finding was in consistent with Sansam et al (2016) in which health workers in Cambodia demonstrated improved knowledge in hand hygiene practice. However, Anargh et al (2013) found unsatisfactory level of knowledge on hand cleansing procedures by WHO.

This study reported a statistically substantial relationship between training and hand hygiene practice, this finding concurs with Randle et al (2014) in which an education intervention showed improved hand hygiene practice. In contrast Salama et al (2013) did not find any correlation between training on hand cleansing procedures and its compliance by the health care workers.

The satisfactory knowledge demonstrated by the study participants reflects on the increased compliance rate with hand hygiene standards as opposed with the previous studies. Also, the availability of the National Infection Prevention and Control strategic program (2014-2018) has played a great role in 
conducting training and dissemination of Information Education Communication (IEC) materials thus improved knowledge.

\subsubsection{Hand hygiene facilities and compliance with hand hygiene standards}

About $60.8 \%$ of the study participants in this study indicated availability of posters at the various water points as an important factor in hand washing promotion. This finding is comparable to that of UNICEF \& UNICEF (2016).whereby availability of posters was a key determinant of compliance with hand hygiene standards. The current study reported inadequate availability of clean running water in which $44.9 \%$ of the study participants indicated unavailability of clean running water at their health facilities. Ngugi (2012) documented water scarcity at the hospitals to be a big hindrance to hand washing practice. The inadequate clean running water in most of the health facilities can be attributed to insufficient storage tanks, inaccessibility to water connection system, unrepaired water pipes and increased demand of water in the county.

The current study reported handiness of alcohol-based hand rub to be low with $69.8 \%$ of the respondents reporting unavailability of alcohol-based hand rub. This finding concurs with the findings of Ndegwa (2014) whereby inconsistent supply of hand rub contributed to poor hand hygiene among the health workers. Abdella et al (2014) also indicated availability of hand rub as a key determinant in hand hygiene practice. However, Smiddy \& Creedon (2015) observed that unavailability of hand rub promoted washing of hands with water and soap which is perceived to be extra effective in hand cleansing than other methods of hand hygiene. Aziz (2013), reported accessibility of hand cleansing facilities to be satisfactory in thirty out of thirtyfour health facilities surveyed in England. The unavailability of hand rub in most of the hospitals is attributed to high cost of purchase.

The current study reported inconsistent availability of hand wipes at various water points, this finding is comparable to the observation made by Maxfield \& Dull (2011) of availability of insufficient hand wipes at the hand washing points. The inconsistent availability of the hand washing soap was evident in the current study. World Health Organization (2012), cited that most hand washing practices in developing countries are unsuccessful due to unavailability of either soap or water to cleanse hands. This may be due to delay in procuring the soap needed in the health facilities and failure to place the soap at hand washing points. Appropriate hand washing of hands and successively dying the hands is important in the success of hand hygiene since poorly dried hands are prone to recontamination as compared to completely dry hands (Ndegwa, 2014).

Srigley, Furness, \& Gardam (2016), observed that unavailability or availability of hand hygiene facilities in the health facilities are the key determinants of effective hand hygiene. Jemal (2018) concluded that hospital units that had substantial hand hygiene facilities had high compliance with hand hygiene guidelines as compared to those with insufficient hand hygiene facilities. Aziz (2013) showed the enormous impact of availability of hand hygiene facilities on hand hygiene practice in which the availability of the materials increased compliance rates by $15 \%$ in United Kingdom.
Tajeddin et al. (2016), also reported availability of hand cleansing materials such as disposal towels for hand drying as a crucial determinant of hand hygiene practice. Ndegwa (2014) cited availability of hand rub in the hospitals as a strong determinant in practicing hand hygiene before interacting with a sick person.

The results from the current study indicate that the compliance rate with had hygiene standards in the health facilities are low. This could because of inadequate cleansing facilities, attitudes of the health personnel towards practicing hand hygiene and unavailability of implementation departments within the health facilities. However, it has been documented that low compliance rates worldwide is attributed to factors such as huge workload, forgetfulness, inadequate running water, disposable hand wipes and soap. (Sansam, 2016).

\subsubsection{Summary of the study}

A total number of three hundred and one health care workers participated in the study. A compliance rate of $49.8 \%$ was revealed in the study. Both female $(56.1 \%)$ and male $(43.9 \%)$ health care workers took part in the study with an average age of 34.8 years. The study showed that there was no relationship between age, gender and hand hygiene standards compliance.

Nurses were the majority professional cadre surveyed. Most of the health care workers had diploma as their upmost education level. The study found out a substantial relationship within level of education, professional cadres and compliance with hand hygiene standards amongst health care workers.

Most of the study participants had gone through training and were conscious about the existence of hand hygiene standards. The study further revealed a statistically significant correlation between training and compliance with hand hygiene standards. A noteworthy number of study participants reported unavailability of clean running water. Also, intermittent handiness of recommended hand-rub, soap, posters, and disposal hand wipes was reported in the study. A statistically significant positive correlation between posters, soap, clean running water, and compliance with hand hygiene standards was evident.

\subsection{Conclusion}

This segment pin points the conclusions deduced from the study results based on every objective of the study.

1. The study concluded that the health care workers had medium level of hand hygiene compliance.

2. The study concluded that professional cadre, education has significant correlation while age and gender of the health care workers had no significant correlation with compliance to hand hygiene standards.

3. The study concluded that having high level of knowledge on hand hygiene standards does not automatically reflect positively on compliance rates .Also, the study concluded that training health workers on hand hygiene compliance has positive significant correlations.

4. The study concluded that the presence of adequate hand washing facilities in hospitals is paramount in practicing hand cleansing. Adequate hand hygiene facilities encourages hand washing.

\subsection{Recommendations}

Www.ijsrp.org 
The following are study recommendations directed to the health facilities and the policy makers;

\subsubsection{Recommendation from the study for the health facilities}

1. Institutional priority for Hand hygiene compliance should be escalated by the infection prevention departments so that the level of compliance should positively reflect on the spread of hospital infections.

2. A safety climate should be created within the health facilities by ensuring that there is constant availability of hand hygiene facilities and regular drills on hand hygiene practice.

3. The hospitals administration should introduce administrative incentive for compliance and sanctions for non-compliance. This will instill a culture of personal responsibility and serve as motivation to perform hand hygiene.

\subsubsection{Recommendation from the study for the policy makers}

1. The study found that there was inadequate supply of hand hygiene facilities therefore the study recommend that the policy makers should adequately budget for such facilities and ensure timely supply.

2. The study recommends that the policy makers come up with laws and regulations that govern the hand hygiene compliance so that those who fail to comply can be accountable for their actions.

\subsubsection{Recommendation for further research}

1. The current study focused only on the level of hand hygiene compliance; therefore, a further research should be done on the linkage between hand cleansing and hospital infections.

2. The current study was conducted at one point in time thus it is recommended that a further study should be done using longitudinal study design.

\section{REFERENCES}

[1] Abdella, N. M., Tefera, M. A., Eredie, A. E., Landers, T. F., Malefia, Y. D., \& Alene, K. A. (2014). Hand hygiene compliance and associated factors among health care providers in Gondar University Hospital, Gondar, North West Ethiopia. BMC Public Health, 14(1), 1.

[2] Alemagno, S. A., Guten, S. M., Warthman, S., Young, E., \& Mackay, D. S. (2010). Online learning to improve hand hygiene knowledge and compliance among health care workers. Journal of Continuing Education in Nursing, 41(10), 463- 471.Doi: 10.3928/00220124-20100610-06

[3] Alemu, B. S., Bezune, A. D., Joseph, J., Gebru, A. A., Ayene, Y. Y., \& Tamene, B. A. (2015). Knowledge and practices of hand washing and glove utilization among the health care providers of shenen gibe hospital, South West Ethiopia. Science, 3(3), 391-397.

[4] Allegranzi, B., Sax, H., Bengaly, L., Richet, H., Minta, D. K., Chraiti, M. N., Sokona, F. M., World Health Organization "Point G" Project Management Committee. (January 01, 2010). Successful implementation of the World Health Organization hand hygiene improvement strategy in a referral hospital in Mali, Africa. Infection Control and Hospital Epidemiology, 31, 2, 133-41.

[5] Alsubaie, S., bin Maither, A., Alalmaei, W., Al-Shammari, A. D., Tashkandi, M., Somily, A. M., \& BinSaeed, A. A. (2013). Determinants of hand hygiene noncompliance in intensive care units. American journal of infection control, 41(2), 131-135.

[6] Anargh, V., Singh, H., Kulkarni, A., Kotwal, A., \& Mahen, A. (2013). Hand hygiene practices among health care workers (HCWs) in a tertiary care facility in Pune. Medical Journal, Armed Forces India, 69(1), 54
[7] Australian Commission on Safety and Quality in Health Care. \& National Health and Medical Research Council (Australia). (2010). Australian guidelines for the prevention and control of infection in healthcare. Canberra, ACT: Australian Government, National Health and Medical Research Council.

[8] Azim, S., Juergens, C., \& McLaws, M. L. (2016). An average hand hygiene day for nurses and physicians: the burden is not equal. American journal of infection control, 44 (7), 777-

781

[9] Aziz, A. M. (2014). Hand hygiene compliance for patient safety. British Journal of Healthcare Management, 20(9), 428-434.

[10] Aziz, A.M. (2013): How better availability of materials improved hand hygiene compliance. British Journal of Nursing April 25-May 82013; 22(8): 458, 460-3.

[11] Baqi, S., Damani, N. N., Shah, S. A., \& Khanani, R. (April 09, 2009). Infection Control at a Government Hospital in Pakistan. International Journal of Infection Control, 5,1 .)

[12] Boyce, J. M., Pittet, D., Healthcare Infection Control Practices Advisory Committee, \& HICPAC/SHEA/APIC/IDSA Hand Hygiene Task Force. (January 01, 2002). Guideline for Hand Hygiene in Health-Care Settings. Recommendations of the Healthcare Infection Control Practices Advisory Committee and the HIPAC/SHEA/APIC/IDSA Hand Hygiene Task Force. American Journal of Infection Control, 30, 8, 1-46.

[13] Day, C. (January 01, 2009). Engaging the nursing workforce: an evidencebased tool kit. Nursing Administration

[14] De Wandel, D., Maes, L., Labeau, S., Vereecken, C., \& Blot, S. (2010). Behavioral determinants of hand hygiene compliance in intensive care units. American Journal of Critical Care: An Official Publication, American Association of Critical-Care Nurses, 19(3), 230-239. Doi: 10.4037/ajcc2010892

[15] Dia, N. M., Ka, R., Dieng, C., Diagne, R., Dia, M. L., Fortes, L., Diop, B. M., Sow, P. S. (January 01, 2008). Prevalence of nosocomial infections in a university hospital (Dakar, Senegal). Medicine ET Maladies Infectieuses, 38 , 5, 270-274

[16] Diller, T., Kelly, J. W., Blackhurst, D., Steed, C., Boeker, S., \& McElveen, D. C. (2014). Estimation of hand hygiene opportunities on an adult medical ward using 24-hour camera surveillance: validation of the HOW2 Benchmark Study. American journal of infection control, 42(6), 602-607.

[17] Esen, S., \& Leblebicioglu, H. (January 01, 2004). Prevalence of nosocomial infections at intensive care units in Turkey: a multicentre 1-day point prevalence study. Scandinavian Journal of Infectious Diseases, 36, 2, 144-8.

[18] Garner, J. S. (January 01, 1996). Guideline for isolation precautions in hospitals. The Hospital Infection Control Practices Advisory Committee. Infection Control and Hospital Epidemiology, 17, 1, 53-80.

[19] Grayson, M. L., \& Russo, P. L. (2009). The national hand hygiene initiative. Medical Journal of Australia, 191(8), 420.

[20] Hebden, J. N., Leaptrot, D., Anttila, A., Allen-Bridson, K., Brooks, J. E., Gross, C., Scalise, E., Wright, M. O. (January 01, 2016). Health careassociated infections studies project: An American Journal of Infection Control and National Healthcare Safety Network data quality collaboration 2016 Case \#1. American Journal of Infection Control, 44, 7 , 761-3. Olive Mugenda and Abel Mugenda (2003). Research Methods: Quantitative and Qualitative Approaches. ACTS Press, Nairobi-Kenya.

[21] Hospital Infection Control Practices Advisory Committee (HICPAC) (January 01, 1995). Recommendations for preventing the spread of vancomycin resistance. Infection Control and Hospital Epidemiology, 16, 2, 105-13.

[22] Jain, S., Edgar, D., Bothe, J., Newman, H., Wilson, A., Bint, B.,\& Harris, J. (2015). Reflection on observation: A qualitative study using practice development methods to explore the experience of being a hand hygiene auditor in Australia. American journal of infection control, 43(12), 13101315

[23] Jang, T. H., Wu, S., Kirzner, D., Moore, C., Youssef, G., Tong, A. ... \& McGeer, A. (2010). Focus group study of hand hygiene practice among healthcare workers in a teaching hospital in Toronto, Canada. Infection Control \& Hospital Epidemiology, 31(2), 144-150

[24] Jemal, S. (2018). Knowledge and Practices of Hand Washing among Health Professionals in Dubti Referral Hospital, Dubti, Afar, Northeast Ethiopia. Advances in preventive medicine, 2018. 
[25] Joshi SK, Joshi A, Park BJ, Aryal UR. (2013). Hand Washing Practice among Health Care Workers in a Teaching Hospital. Journal of Nepal Health Research Council, 11 (23): 1

[26] Kalata, N. L., Kamange, L., \& Muula, A. S. (2013). Adherence to hand hygiene protocol by clinicians and medical students at Queen Elizabeth Central Hospital, Blantyre-Malawi. Malawi Medical Journal, 25(2), 50-52.

[27] Kenya National Bureau of Statistics (KNBS) and ICF Macro. (2010). Kenya Demographic and Health Survey. Calverton, Maryland: KNBS and ICF Macro.

[28] Kenya, G. (2011). Kenya County Fact Sheets. Uasin Gishu County.

[29] Kihungi, L., Ndinda, M., Dolan, S., Wesangula, E., Ndegwa, L., Owiso, G., ... \& Rabinowitz, P. (2020). Improvement of Infection Prevention and Control Practices Using Quality Improvement Approach in Two Model Hospitals in Kenya. Infection Control \& Hospital Epidemiology, 41(S1), s286-s287.

[30] Kingston, L., O'Connell, N. H., \& Dunne, C. P. (2016). Hand hygiene-related clinical trials reported since 2010: a systematic review. Journal of Hospital Infection, 92(4), 309-320.

[31] Kleinpell, R. M., Munro, C. L., \& Giuliano, K. K. (2008). Targeting health care-associated infections: evidence-based strategies.

[32] Lam, B. C., Lee, J., \& Lau, Y. L. (January 01, 2004). Hand hygiene practices in a neonatal intensive care unit: a multimodal intervention and impact on nosocomial infection. Pediatrics, 114, 5, 565-71.

[33] Langoya, C. O., \& Fuller, N. J. (2015). Assessment of knowledge of hand washing among health care providers in Juba Teaching Hospital, South Sudan. South Sudan Medical Journal, 8(3), 60-62.

[34] Magiorakos, A. P., Suetens, C., Boyd, L., Costa, C., Cunney, R., Drouvot, V., Farrugia, C. Monnet, D. L. (January 01, 2009). National hand hygiene campaigns in Europe, 2000-2009. Euro Surveillance: Bulletin Europeen Sur Les Maladies Transmissibles $=$ European $\quad$ Communicable Disease Bulletin, 14, 17.)

[35] Mahfouz, A. A., El Gamal, M. N., \& Al-Azraqi, T. A. (2013). Hand hygiene non-compliance among intensive care unit health care workers in Aseer Central Hospital, south-western Saudi Arabia. International Journal of Infectious Diseases, 17(9), e729-e732.

[36] Mahfouz, A.A., El Gamal, M.N., \& Al-Azraqi, T.A. (2013): Hand Hygiene non-compliance among Intensive Care Unit healthcare workers in Aseer Central Hospital, South Western Saudi Arabia. International Journal of Infectious Diseases September 2013; 17(9): e729-32.

[37] Maingi, S. M. (2015). Factors influencing compliance with hand hygiene Guidelines among healthcare providers in Kenya: a case of Embu Level Five hospital, Embu County (Doctoral dissertation, University of Nairobi)

[38] Mani, A., Shubangi, A. M., \& Saini, R. (2010). Hand hygiene among health care workers. Indian Journal of Dental Research, 21(1), 115.

[39] Marjadi, B., \& McLaws, Muhumuza, C., Gomersall, J. S., Fredrick, M. E., Atuyambe, L., Okiira, C., Mukose, A., \& Ssempebwa, J. (January 01, 2015). Health care worker hand hygiene in the pediatric special care unit at Mulago National Referral Hospital in Uganda: a best practice implementation project. International Journal of Evidence-Based Healthcare, 13, 1, 19-27.

[40] M. L. (January 01, 2010). Hand hygiene in rural Indonesian healthcare workers: barriers beyond sinks, hand rubs and in-service training. The Journal of Hospital Infection, 76, 3, 256-60. Mathur, P. (2011). Hand hygiene: back to the basics of infection control. The Indian journal of medical research, 134(5), 611.

[41] Maxfield, D., \& Dull, D. (January 01, 2011). Influencing hand hygiene at spectrum health. Physician Executive, 37, 3.)

[42] Mortell, M. (2012). Hand hygiene compliance: is there a theory-practiceethics gap? British Journal of Nursing, 21(17), 1011-1014.

[43] Ndegwa, L. (2014): Assessment of hand hygiene practices and usage of alcohol-based hand sanitizer in three Kenyan hospitals, 2011-12. A paper presented at a poster Abstract session at a meeting of Infectious Diseases Society of America (ID Week, October 2014). Infection Control Program. Annals of Internal Medicine, 130, 2, 126- 30

[44] Ngugi, S. K. (2012). Hand hygiene practices among health care workers in the Kenyatta National Hospital newborn unit (Doctoral dissertation, University of Nairobi, Kenya).

[45] Ojong, I. N., Etim, M. I., Nlumanze, F. F., \& Akpan, M. I. (2014). The practice of hand washing for the prevention of Nosocomial infections among nurses in general hospital Ikot Ekpene, Akwa Ibom State, Nigeria. Advanced Applied $\quad$ Science Research, 6(1), 97-101.
[46] Peacock, J. E. J., Marsik, F. J., \& Wenzel, R. P. (January 01, 1980) Methicillin-resistant Staphylococcus aureus: introduction and spread within a hospital. Annals of Internal Medicine, 93, 4, 526-32

[47] Pittet, D., Allegranzi, B., Boyce, J., \& World Health Organization World Alliance for Patient Safety First Global Patient Safety Challenge Core Group of Experts. (January 01, 2009). The World Health Organization Guidelines on Hand Hygiene in Health Care and their consensus recommendations. Infection Control and Hospital Epidemiology, 30, 7, 61122

[48] Pittet, D., Mourouga, P., \& Perneger, T. V. (January 01, 1999). Compliance with handwashing in a teaching hospital

[49] Randle, J., Arthur, A., Vaughan, N., Wharrad, H., \& Windle, R. (2014). An observational study of hand hygiene adherence following the introduction of an education intervention. Journal of infection prevention, 15(4), 142-147.

[50] Rocha, L. A., Nunes, M. J., \& Gontijo Filho, P. P. (2012). Low compliance to handwashing program and high nosocomial infection in a Brazilian hospital. Interdisciplinary perspectives on infectious diseases, 2012.

[51] Said, D. (2006). Effect of Hand Hygiene Procedures on Skin Biomarkers (Doctoral dissertation, University of Cincinnati)

[52] Sakihama, T., Honda, H., Saint, S., Saint, S., Fowler, K. E., Shimizu, T., Tokuda, Y., Mihashi, M. (January 01, 2016). Hand hygiene adherence among health care workers at Japanese hospitals: A multicenter observational study in Japan. Journal of Patient Safety, 12, 1, 11-17.

[53] Salama, M. F., Jamal, W. Y., Al Mousa, H., Al-AbdulGhani, K. A., \& Rotimi, V. O. (2013). The effect of hand hygiene compliance on hospital-acquired infections in an ICU setting in a Kuwaiti teaching hospital. Journal of infection and public health, 6(1), 27-34

[54] Samuel, R., Almedom, A. M., Hagos, G., Albin, S., \& Mutungi, A. (2005). Promotion of handwashing as a measure of quality of care and prevention of hospital-acquired infections in Eritrea: the Keren study. African health sciences, 5(1), 4-13.

[55] Sansam, S., Yamamoto, E., Srun, S., Sinath, Y., Moniborin, M., Sim, K. B ... \& Hamajima, N. (2016). Assessment of hand hygiene compliance after hand hygiene education among health care workers in Cambodia Nagoya Journal of Medical Science, 78(2), 151- 162.

[56] Sethi, A. K., Acher, C. W., Kirenga, B., Mead, S., Donskey, C. J., \& Katamba, A. (2012). Infection control knowledge, attitudes, and practices among healthcare workers at Mulago Hospital, Kampala, Uganda. Infection Control \& Hospital Epidemiology, 33(9), 917-923.

[57] Seto, W. H., Yuen, S. W., Cheung, C. W., Ching, P. T., Cowling, B. J., \& Pittet, D. (January 01, 2013). Hand hygiene promotion and the participation of infection control link nurses: an effective innovation to overcome campaign fatigue. American Journal of Infection Control, 41, 12, 1281-3.

[58] Sickbert-Bennett, E. E., DiBiase, L. M., Willis, T. M. S., Wolak, E. S., Weber, D. J., \& Rutala, W. A. (2016). Reduction of healthcare-associated infections by exceeding high compliance with hand hygiene practices. Emerging infectious diseases, 22(9), 1628.

[59] Smiddy, M. P., O', C. R., \& Creedon, S. A. (March 01, 2015). Systematic qualitative literature review of health care workers' compliance with hand hygiene guidelines. Ajic: American Journal of Infection Control, 43, 3, 269274.

[60] Smith, S. M. S. (March 01, 2009). A review of hand-washing techniques in primary care and community settings. Journal of Clinical Nursing, 18, 6, 786790.

[61] Srigley, J. A., Furness, C. D., \& Gardam, M. (2016). Interventions to improve patient hand hygiene: a systematic review. Journal of Hospital Infection, 94(1), 2329.

[62] Sunkesula, V. C., Meranda, D., Kundrapu, S., Zabarsky, T. F., McKee, M., Macinga, D. R., \& Donskey, C. J. (2015). Comparison of hand hygiene monitoring using the 5 Moments for Hand Hygiene method versus a wash in-wash out method. American journal of infection control, 43(1), 16-19.

[63] Tajeddin, E., Rashidan, M., Razaghi, M., Javadi, S. S., Sherafat, S. J., Alebouyeh, M., ... \& Zali, M. R. (2016). The role of the intensive care unit environment and health-care workers in the transmission of bacteria associated with hospital acquired infections. Journal of infection and public health, 9(1), 13- 23 .

[64] Takahashi, I., \& Turale, S. (January 01, 2010). Evaluation of individual and facility factors that promote hand washing in aged-care facilities in Japan. Nursing \& Health Sciences, 12, 1, 127-34. 
[65] Taneja, J., \& Mishra, B. (2015). Promotion of successful hand hygiene practices in the intensive care units of a tertiary care hospital. Journal of Patient Safety \& Infection Control, 3(3), 130-133.

[66] Trampuz, A., \& Widmer, A. F. (January 01, 2004). Hand hygiene: a frequently missed lifesaving opportunity during patient care. Mayo Clinic Proceedings, 79, 1, 109-16 Water, Sanitation and Hygiene in Health Care Facilities: Status in Low- and Middle-income Countries and Way Forward. (2015). United Nations Children's Fund (UNICEF).

[67] Watson, J. A. (2016). Role of a multimodal educational strategy on health care workers' handwashing. American journal of infection control, 44(4), 400-404.

[68] Whitby, M., McLaws, M. L., \& Ross, M. W. (January 01, 2006). Why healthcare workers don't wash their hands: a behavioral explanation. Infection Control and Hospital Epidemiology, 27, 5, 484-92.

[69] WHO launches global patient safety challenge; issues guidelines on hand hygiene in health care? (2005). Indian Journal of Medical Sciences, 59(10), 461-463.

[70] World Health Organization. \& World Health Organization. (2009). A guide to the implementation of the WHO multimodal hand hygiene improvement strategy: Guide to implementation. Geneva, Switzerland: World Health Organization

[71] World Health Organization. (2009). WHO guidelines on hand hygiene in health care: First global patient safety challenge: clean care is safer care. Geneva, Switzerland: World Health Organization, Patient Safety.
[72] World Health Organization. (2010). WHO guidelines on hand hygiene in health care: First global patient safety challenge: clean care is safer care. Geneva: WHO

[73] Zakeri, H., Ahmadi, F., Rafeemanesh, E., \& Saleh, L. A. (2017). The knowledge of Hand hygiene among the healthcare workers of two teaching hospitals in Mashhad. Electronic physician, 9(8), 5159.

\section{AUTHORS}

First Author - Sharon Jerop Koech, Research scholar; Email: sharonkoech254@gmail.com

Second Author - Dr. Jackim Nyamari, Lecturer, Department of Environmental and Occupational Health, Kenyatta University NYAMARI.JACKIM@ku.ac.ke

Third Author - Dr. Eunice Njogu, Lecturer, Department of Food Nutrition and Dietetics, Kenyatta University

NJOGU.EUNICE@ku.ac.ke 